\title{
Population Pharmacokinetics of Revefenacin in Patients with Chronic Obstructive Pulmonary Disease
}

\author{
Arthur Lo $^{1}$ (I) $\cdot$ Marie T. Borin ${ }^{1} \cdot$ David L. Bourdet $^{1}$
}

Published online: 29 October 2020

(c) The Author(s) 2020

\begin{abstract} II and two phase III studies. mixed-effects modeling. metabolized to THRX-195518. NCT02512510

\section{Introduction}

Revefenacin is a long-acting, lung-selective muscarinic receptor antagonist formulated as a nebulized inhalation solution for use with a standard jet nebulizer for the once-daily maintenance treatment of patients with chronic obstructive pulmonary disease (COPD). Clinical data demonstrate the clinical efficacy and safety of revefenacin in
\end{abstract}

Background and Objectives Revefenacin is a lung-selective, long-acting muscarinic antagonist indicated for the maintenance treatment of patients with chronic obstructive pulmonary disease. The objectives of this analysis were to evaluate the pharmacokinetics of revefenacin and its major metabolite (THRX-195518) in patients with chronic obstructive pulmonary disease, and identify significant covariates affecting revefenacin disposition using a population pharmacokinetic approach based on plasma concentration-time data obtained after single- and repeated-dose once-daily administration in three phase

Methods Plasma concentrations of revefenacin and THRX-195518 following once-daily administration via nebulization at a dose levels ranging from 22-700 $\mu \mathrm{g}$ in 935 patients (488 men, 447 women; age 41-88 years) were analyzed using nonlinear

Results Plasma revefenacin pharmacokinetics was best described by a two-compartment model with first-order absorption and elimination. Pharmacokinetic parameters for THRX-195518 were estimated using a sequential approach, where the concentration-time profiles were fit to a combined model. The formation of the metabolite in each subject was estimated to be a fixed fraction of the individually estimated (post-hoc) clearance rate of revefenacin. Four statistically significant covariates were identified: for revefenacin, age on apparent clearance and body weight on apparent intercompartment clearance, for THRX-195518, age on apparent clearance and body weight on the fraction of revefenacin apparent clearance that was

Conclusions None of the identified statistically significant covariates were associated with a clinically meaningful effect on revefenacin or THRX-195518 exposure in patients with chronic obstructive pulmonary disease.

Registration ClinicalTrials.gov identifier number NCT03064113, NCT01704404, NCT02040792, NCT02459080, and

Electronic supplementary material The online version of this article (https://doi.org/10.1007/s40262-020-00938-3) contains supplementary material, which is available to authorized users.

Arthur Lo

alo@theravance.com

1 Theravance Biopharma US, Inc., 901 Gateway Blvd, South San Francisco, CA 94080, USA patients with COPD. In phase II and III studies, once-daily administration of revefenacin significantly improved the forced expiratory volume compared with placebo [1-3]. Revefenacin was also investigated in a 52-week safety study [4].

The pharmacokinetic (PK) properties of inhaled revefenacin were investigated in patients with COPD. In three phase II studies [1, 2] and two phase III studies [3], plasma revefenacin concentrations following inhaled administration were low $(0.16 \mathrm{ng} / \mathrm{mL})$ and declined rapidly from the initial maximum concentration, with a slow apparent terminal elimination phase. Limited accumulation for revefenacin and THRX-195518 in plasma was observed after repeated administration [2]. Renal elimination of revefenacin was very low after inhaled administration; $<1 \%$ of the dose was excreted in urine. Revefenacin was rapidly and extensively 


\section{Key Points}

The objectives were to evaluate the pharmacokinetics of revefenacin and its metabolite (THRX-195518) in patients with chronic obstructive pulmonary disease.

A population pharmacokinetic approach was used based on plasma concentration-time data from 935 subjects in three phase II and two phase III studies.

No clinically significant impacts of patient and disease characteristics on revefenacin and THRX-195518 systemic exposure were identified.

converted to THRX-195518 after inhaled administration. Revefenacin is approximately three- to ten-fold more potent than THRX-195518, which dissociates more rapidly from human M3 receptors [5]. The major metabolic pathway after intravenous (IV) or oral administration of revefenacin identified in a human absorption, distribution, and metabolism, and excretion study is the conversion of revefenacin to THRX-195518 via hydrolysis [6]. Revefenacin had low absolute bioavailability (2.8\%) after oral administration and was eliminated primarily in feces after oral or IV administration, suggesting extensive hepatobiliary elimination [6].

This study elucidates the population pharmacokinetics of revefenacin and THRX-195518 in patients with COPD using a sequential modeling approach to first characterize revefenacin pharmacokinetics, followed by THRX-195518, and to identify significant covariates that impact the PK parameters of revefenacin and THRX-195518 in patients with COPD. The final population PK model in patients with COPD was used to determine the magnitude of effect of the intrinsic and extrinsic factors on the steady-state systemic exposures to revefenacin and THRX-195518.

\section{Methods}

\subsection{Patient Population and Study Design}

All participants gave written informed consent before any study-related procedures, and the protocols were approved by the appropriate institutional review board [Electronic Supplementary Material (ESM)] for each study site and were carried out in concordance with ICH Guidelines for Good Clinical Practice [1-3, 7]. Data for the analysis were obtained from three phase II studies (studies 1, 2, and 3) and two phase III studies (studies 4 and 5) in patients with COPD. The inclusion criteria for each study are outlined in the ESM. Participants in the phase II studies received revefenacin once daily as a nebulized solution at doses from 22 to $700 \mu \mathrm{g}$ for 1,7 , or 28 days. Participants in the phase III studies received revefenacin once daily as a nebulized solution at 88 or $175 \mu \mathrm{g}$ for 12 weeks. Pharmacokinetic sampling times are summarized in Table S1 of the ESM.

\subsubsection{Study 1}

Study 1 was a phase II, single-dose, randomized, doubleblind, active- and placebo-controlled, four-period crossover study (NCT03064113) designed to examine the pharmacodynamic effects of two dose levels (350 and $700 \mu \mathrm{g}$ ) of revefenacin inhalation solution as a single dose administered in a population ( $n=32$, all with evaluable PK data) with moderate to severe COPD [2]. Study treatment administered in the four periods included the following: single doses of 350 and $700 \mu \mathrm{g}$ of revefenacin via a nebulizer, active-control agent ipratropium bromide $(500 \mu \mathrm{g})$, and placebo. Each subject underwent a washout of 7-12 days between dose administrations. Serial blood samples were collected from pre-dose to up to $24 \mathrm{~h}$ post-dose.

\subsubsection{Study 2}

Study 2 was a phase II, double-blind, randomized, fiveperiod incomplete block, crossover study (NCT01704404) in which six dose levels of revefenacin inhalation solution $(22,44,88,175,350$, and $700 \mu \mathrm{g})$ and placebo were evaluated in a population $(n=62,61$ patients with evaluable PK data) with moderate to severe COPD [2]. Serial blood samples were collected from pre-dose to up to $24 \mathrm{~h}$ post-dose on days 1 and 7 .

\subsubsection{Study 3}

Study 3 was a phase II, randomized, double-blind, placebocontrolled, parallel-group study (NCT02040792) [1] in which four dose levels of revefenacin inhalation solution $(44,88,175$, and $350 \mu \mathrm{g})$ and placebo for 28 days were evaluated in a population $(n=355,34$ patients where PK data were collected) with moderate to severe COPD. Serial blood samples were collected from pre-dose to up to $72 \mathrm{~h}$ post-dose on day 28.

\subsubsection{Studies 4 and 5}

Studies 4 and 5 were identical phase III, randomized, double-blind, active-controlled, parallel-group, multicenter studies (NCT02459080 and NCT02512510) [3] in which two doses (88 and $175 \mu \mathrm{g}$ ) of revefenacin inhalation solution or placebo were administered for 12 weeks in a population ( $n=1230,808$ patients with evaluable PK data) with moderate to very severe COPD. Of these patients, $304(37.6 \%)$ 
were concomitantly taking long-acting $\beta$-agonist (LABA)/ inhaled corticosteroid (ICS) therapy. Patients with moderate to severe hepatic impairment were excluded from the study. Blood samples were collected on days 1, 15, 29, 57, and 84 .

\subsection{Pharmacokinetic Sample Collection and Bioanalysis}

Plasma samples from the three phase II and the two phase III studies were analyzed at Q2 Solutions (formerly Quintiles, Inc. and Advion Bioservices, Inc., Ithaca, NY, USA) using validated liquid chromatography with tandem mass spectrometry methods. The lower limit of quantification for revefenacin and THRX-195518 in plasma was $0.005 \mathrm{ng} /$ $\mathrm{mL}$ and $0.05 \mathrm{ng} / \mathrm{mL}$ for the phase II studies and 0.0005 and $0.005 \mathrm{ng} / \mathrm{mL}$, respectively, for the phase III studies. The lower limit of quantification for revefenacin in the phase III studies represents a ten-fold increase in assay sensitivity relative to the assay used for the phase II studies to allow for the quantification of revefenacin in the trough samples collected in the phase III studies.

\subsection{Population Modeling}

Data from all studies were pooled for the integrated population PK analysis using nonlinear mixed-effects modeling using the first-order conditional estimation method with interaction in NONMEM 7.2 (ICON, Dublin, Ireland) and PLT Tools (PLT Soft, San Francisco, USA). Models were compared using the mean value of the objective function computed as -2 times the log-likelihood.

One-, two-, and three-compartment models were considered to describe revefenacin and THRX-195518 concentration-time data [8]. The formation rate of THRX-195518 was defined in the model to be a fraction of the clearance rate of revefenacin from the central compartment. All models assumed lognormal distributions of the individual PK parameters, with a mixed residual error model. A studyspecific additive residual error for revefenacin was used for the observations from phase III because of the ten-fold difference sensitivity in the assay.

A sequential approach was used whereby the revefenacin data were initially fit to the revefenacin model. Then, the THRX-195518 data were fit to the combined model where PK parameters for revefenacin for each subject were fixed to the individually estimated post-hoc PK parameters from the revefenacin model. Inter-individual error terms for the revefenacin PK parameters were included in the fit to the THRX-195518 data to minimize the effect of bias.

A simultaneous modeling strategy was also evaluated in addition to the sequential approach; the parameters for revefenacin and THRX-195518 were simultaneously estimated to investigate the potential bias of the sequential approach because of the presence of shrinkage in the post-hoc individual parameters of the revefenacin model. However, the simultaneous approach introduced the potential issue of the propagation of uncertainty in model and parameter estimates from/to revefenacin to/from THRX-195518 with the known risk of increasing run-time and model instability.

Inter-occasion variability was evaluated by comparing the measured plasma concentrations of revefenacin and THRX195518 to determine the presence of any differences between study visits. Concentrations below the limit of quantification were discarded in this analysis (M1) as the increased sensitivity of the revefenacin assay in the phase III studies allowed for the characterization of trough concentrations in all patients. A sensitivity analysis was conducted by repeating the analysis for revefenacin using the likelihood maximization (M3) method [9].

\subsection{Subject Covariate Analysis}

Intrinsic covariates of age, weight, sex, race, smoking status, creatinine clearance, liver enzymes (alanine aminotransferase, aspartate aminotransferase, and total bilirubin), body mass index, and baseline forced expiratory volume in $1 \mathrm{~s}$ $\left(\mathrm{FEV}_{1}\right)$ were tested on the PK parameters of apparent revefenacin clearance $(\mathrm{CL} / \mathrm{F})$, apparent revefenacin volumes of the central $\left(V_{1} / \mathrm{F}\right)$ and peripheral $\left(V_{2} / \mathrm{F}\right)$ compartments, apparent revefenacin intercompartmental clearance $(Q / F)$, the fraction of CL/F that is metabolized to THRX-195518 $\left(\mathrm{F}_{\mathrm{met}}\right)$, apparent THRX-195518 clearance $\left(\mathrm{CL}_{\mathrm{met}} / \mathrm{F}\right)$, apparent THRX-195518 volumes of the central $\left(V_{3} / \mathrm{F}\right)$ and peripheral $\left(V_{4} / \mathrm{F}\right)$ compartments, and apparent THRX-195518 intercompartmental clearance $\left(Q_{\text {met }} / F\right)$.

Continuous covariates were normalized to the population median values and modeled using the general equation:

$\theta_{i}=\theta_{\text {Typical }}\left(\frac{\operatorname{Cov}_{i}}{\operatorname{Cov}_{\text {Median }}}\right)^{\theta_{\text {eff }}}$

where $\theta_{i}$ is the value of the parameter for the $i$ th individual, $\theta_{\text {Typical }}$ is the typical value of the parameter in the population, $\operatorname{Cov}_{i}$ is the value of the covariate for the individual, $\operatorname{Cov}_{\text {Median }}$ is the median value of the covariate in the study population, and $\theta_{\text {eff }}$ is the effect of the covariate on the parameter.

Categorical covariates were modeled using the general equation:

$\theta_{i}=\theta_{\text {Typical }} \times \theta_{\text {eff }}^{\mathrm{K}_{\text {ind }}}$

where $K_{\text {ind }}$ is an indicator variable representing one form of the categorical variable, e.g., men are coded as 1 and women as 0 . 


\subsection{Model Selection and Evaluation}

Model selection was based on a comparison of the objective function value and visual inspection of goodness-of-fit plots. Significant parameter covariate relationships identified were included in an initial full PK model (a decrease of 6.63 points in the value of the objective function equivalent to a two-sided $\alpha=0.01$ ). Covariates were subsequently excluded from the model using a stepwise deletion method in which the statistical significance of each parameter-covariate relationship was tested using a likelihood ratio test (an increase of 10.83 points in the value of the objective function, equivalent to a two-sided $\alpha=0.001)$. Evaluation of the model fit was conducted using a bootstrap analysis (200 replicates) and a visual predictive check of the final model using 1000 simulated data sets.

\subsection{Simulation of Exposures in Phase III Studies}

The steady-state exposure in each subject in the two phase III studies was simulated using the individual post-hoc parameter estimates from the final population PK model to compare exposures between smokers and nonsmokers, patients with and without concomitant medications with known potential drug-drug interactions, and between patients with and without LABA/ICS use. Nonlinear mixed-effects modeling was used to simulate the steady-state plasma concentrations at $0,0.01,0.25,0.5,1,2,4,6,8,12,16$, and $24 \mathrm{~h}$ after the start of nebulization using individually estimated $\mathrm{PK}$ parameters $\left(\mathrm{CL} / \mathrm{F}, V_{1} / \mathrm{F}, Q / \mathrm{F}, V_{2} / \mathrm{F}\right)$ for each subject as determined by the final population PK model. The dose and interval were obtained from the study data. The duration of nebulization was not recorded in the phase III studies and was assumed to be $10 \mathrm{~min}$ for all patients based on observed dosing durations in prior studies. Steady-state exposure $\left(\mathrm{AUC}_{0-24}\right)$ was calculated using linear trapezoidal approximation and $C_{\max }$ was the maximum observed post-dose concentration in the simulated plasma concentration-time profile.

\section{Results}

A total of 10,043 and 10,717 measurable concentrations of revefenacin and THRX-195518, respectively, were utilized in this analysis. The median, minimum, and maximum number of observations from each patient were 10, 1, and 59, respectively, for revefenacin and 9,1 , and 75 , respectively, for THRX-195518.

A fraction of pretreatment samples in the phase III studies collected from each subject on day 1 had quantifiable revefenacin concentrations (22\%) and THRX-195518 concentrations (4\%), the majority of which were near the lower limit of quantification. A sensitivity analysis was conducted with and without the inclusion of quantifiable pretreatment concentrations utilizing an additional term to estimate a residual additive error.

\subsection{Patients}

The baseline demographics and clinical characteristics of patients in this analysis are listed in Table 1. The PK analysis population comprised 935 patients aged $41-88$ years, weight $38.5-192 \mathrm{~kg}$, estimated creatinine clearances from 22 to $151 \mathrm{~mL} / \mathrm{min}$, and baseline $\mathrm{FEV}_{1}$ values from 44 to $2962 \mathrm{~mL}$. The study population was $52.2 \%$ men; $46 \%$ of patients were current smokers; $32.5 \%$ of patients in the PK analysis population were receiving concomitant LABA/ICS therapy. Pharmacokinetic sampling times used in the analysis are described by study in Table S1 of the ESM.

\subsection{Revefenacin}

Systemic revefenacin pharmacokinetics was best described by a two-compartment model with fixed first-order absorption $\left(K_{\mathrm{a}}\right)$ from the dosing depot (representing the lung). Terms used include relative bioavailability (F1) and distribution and elimination parameterized by $\mathrm{CL} / \mathrm{F}, V_{1} / \mathrm{F}, Q / \mathrm{F}$, and $V_{2} / \mathrm{F}$ with inter-individual variability (IIV) terms on $\mathrm{CL} / \mathrm{F}$, $V_{1} / \mathrm{F}, Q / \mathrm{F}, V_{2} / \mathrm{F}$, and $\mathrm{F} 1$ with a combination additive and proportional residual error model for phase II study data and a separate proportional residual error model for phase III study data (Fig. 1). The F1 in the structural model included a separate categorical covariate term to represent observations from Study 1 to reflect the observed lower exposures, and a continuous covariate term to represent the relationship between dose and bioavailability.

In the final model (Table 2), the population estimate of $\mathrm{CL} / \mathrm{F}$ was $668 \mathrm{~L} / \mathrm{h}$ with an IIV of $56.2 \%$; the typical $V_{1} / \mathrm{F}$ was estimated to be $867 \mathrm{~L}$ with an IIV of $26.9 \%$; Q/F was estimated to be $2607 \mathrm{~L} / \mathrm{h}$ with an IIV of $31.0 \%$; and the population value of $V_{2} / \mathrm{F}$ was estimated to be $15,495 \mathrm{~L} / \mathrm{h}$ with an IIV of 52.2\%. First-order absorption was fixed at 200/h, the effect of Study 1 on F1 was 55.3\% with an IIV of $33.7 \%$, and the effect of the dose on F1 was 0.0987 .

The analysis was repeated using the maximum likelihood (M3) method to assess the potential risk of bias. A sensitivity analysis conducted on the final structural model to compare the parameter estimates using the M1 and M3 methods did not show significant differences in the parameter estimates, indicating the absence of bias in the parameter values estimated with the M1 method. The corresponding $\eta$-shrinkage for the revefenacin model was $13.5 \%$ for $\mathrm{CL} / \mathrm{F}, 42.5 \%$ for $V_{1} / \mathrm{F}, 33.7 \%$ for $Q / \mathrm{F}$, and $46.8 \%$ for $V_{2} / \mathrm{F}$. 
Table 1 Baseline demographics and clinical characteristics for the pharmacokinetic analysis population

\begin{tabular}{lll}
\hline $\begin{array}{l}\text { Abbreviation for continuous } \\
\text { covariates }\end{array}$ & Characteristic & $(N=935)$ \\
\hline AGE & Age, mean (SD), years & $63.5(8.72)$ \\
& Sex, male, \% & 52.2 \\
& Race, white, $\%$ & 90.3 \\
WT & Body weight, mean (SD), kg & $83.3(21.8)$ \\
BMI & Body mass index, mean (SD), $\mathrm{kg} / \mathrm{m}^{2}$ & $29.0(6.97)$ \\
CrCL & Creatinine clearance, mean (SD), mL/min & $71.7(20.7)$ \\
& Smoker (current), \% & 46.0 \\
& Concomitant LABA/ICS, \% & 32.5 \\
BLFEV1 & Baseline forced expiratory volume in 1 s, mean (SD), mL & $1330(487)$ \\
BALT & ALT, mean (SD), IU/L & $20.3(11.5)$ \\
BAST & AST, mean (SD), IU/L & $21.4(9.38)$ \\
BTBIL & Total bilirubin, mean (SD), $\mu$ mol/L & $6.57(3.83)$ \\
NEBTIME & Nebulization time, mean (SD), min & $10.3(2.08)$
\end{tabular}

$A L T$ alanine aminotransferase, AST aspartate aminotransferase, LABA/ICS long-acting beta-agonist or inhaled corticosteroid, $S D$ standard deviation

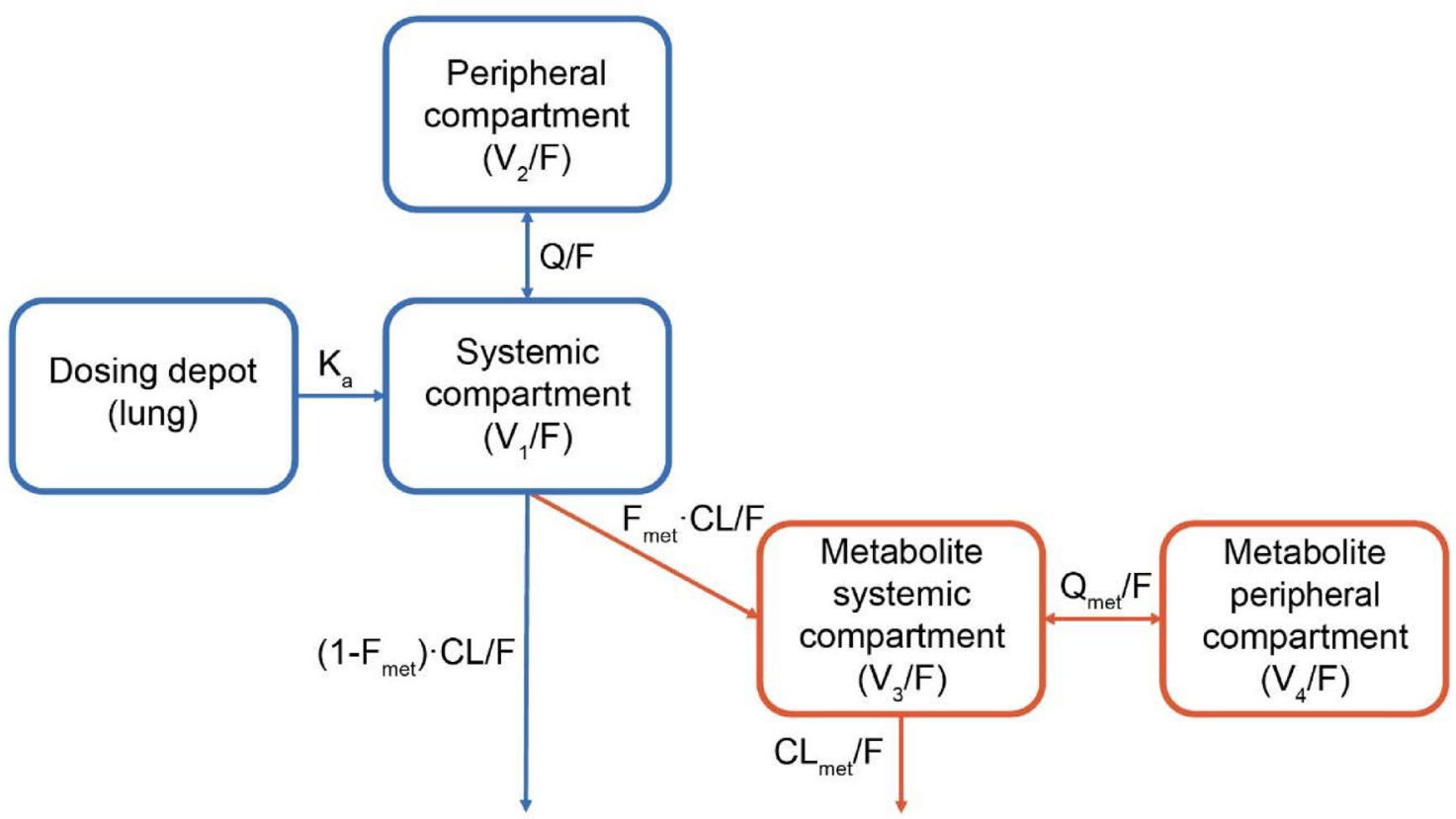

Fig. 1 Schematic of the revefenacin and THRX-195518 combined pharmacokinetic (PK) model. $C L_{m e} / F$ apparent THRX-195518 clearance, $\mathrm{F}_{m e t}$ fraction of revefenacin clearance that is metabolized to THRX-195518, $K_{a}$ first-order absorption, $Q / F$ apparent revefenacin intercompartmental clearance, $Q_{m e t} / F$ apparent THRX-195518

\subsection{THRX-195518}

The appearance of the metabolite THRX-195518 in the systemic circulation was assumed to be a fraction of the revefenacin cleared from the systemic circulation and is structurally unidentifiable. It was not possible to simultaneously intercompartmental clearance, $V_{l} / F$ apparent revefenacin volume of the central compartment, $V_{2} / F$ apparent revefenacin volume of the peripheral compartment, $V_{3} / F$ apparent THRX-195518 volume of the central compartment, $V_{4} / F$ apparent THRX-195518 volume of the peripheral compartment

estimate $\mathrm{F}_{\text {met }}, V_{3} / \mathrm{F}$, and $\mathrm{CL}_{\text {met }} / \mathrm{F}$ based on the measured concentration as the total amount of THRX-195518 formed per dose is unknown. The approach used to address the parameter identifiability problem was to estimate $\mathrm{CL}_{\text {met }} / \mathrm{F}$ and $V_{3} / \mathrm{F}$ while fixing $\mathrm{F}_{\text {met }}$. The value of $\mathrm{F}_{\text {met }}$ was chosen to match the total fraction of the dose recovered as THRX-195518 in 
Table 2 Final pharmacokinetic model parameter estimates

\begin{tabular}{|c|c|c|c|}
\hline & Description & $\begin{array}{l}\text { Population estimate } \\
\text { (\% RSE) }\end{array}$ & $\begin{array}{l}\text { Inter-individual } \\
\text { variability }(\%)\end{array}$ \\
\hline \multirow[t]{9}{*}{ Revefenacin } & $\mathrm{CL} / \mathrm{F}, \mathrm{L} / \mathrm{h}$ & $668(3.17)$ & 56.2 \\
\hline & $V_{1} / \mathrm{F}, \mathrm{L}$ & $867(3.77)$ & 26.9 \\
\hline & $Q / \mathrm{F}, \mathrm{L} / \mathrm{h}$ & $2607(2.51)$ & 31.0 \\
\hline & $V_{2} / \mathrm{F}, \mathrm{L}$ & $15,495(4.88)$ & 52.2 \\
\hline & $K_{\mathrm{a}}, \mathrm{L} / \mathrm{h}$ & 200 (fixed) & 0 \\
\hline & Study 1 effect on F1 & $0.553(7.09)$ & 33.7 \\
\hline & Dose effect on F1 & $0.0987(4.80)$ & N/A \\
\hline & Age effect on CL/F & $-0.559(26.0)$ & N/A \\
\hline & Weight effect on $Q / F$ & $0.485(12.4)$ & N/A \\
\hline \multirow[t]{8}{*}{ THRX-195518 } & $\mathrm{CL}_{\mathrm{met}} / \mathrm{F}, \mathrm{L} / \mathrm{h}$ & $53.2(1.84)$ & 36.0 \\
\hline & $V_{3} / \mathrm{F}, \mathrm{L}$ & $20.4(3.62)$ & 52.1 \\
\hline & $\mathrm{Q}_{\mathrm{met}} / \mathrm{F}, \mathrm{L} / \mathrm{h}$ & $36.3(4.31)$ & 0 \\
\hline & $V_{4} / \mathrm{F}, \mathrm{L}$ & $35.8(5.44)$ & 0 \\
\hline & $\mathrm{F}_{\mathrm{met}}$ & 0.21 (fixed) & 0 \\
\hline & Correlation between $\mathrm{CL}_{\text {met }}$ and $V_{3}$ & $1.45(7.46)$ & N/A \\
\hline & Age effect on $\mathrm{CL}_{\text {met }} / \mathrm{F}$ & $-0.777(13.1)$ & N/A \\
\hline & Weight effect on $\mathrm{F}_{\text {met }}$ & $-0.406(18.1)$ & N/A \\
\hline
\end{tabular}

$C L / F$ apparent clearance, $C L_{m e} / F$ apparent THRX-195518 clearance, $F 1$ bioavailability, $F_{\text {met }}$ fraction of revefenacin clearance that is metabolized to THRX-195518, $K_{a}$ first-order absorption, N/A not applicable, $Q / F$ apparent revefenacin intercompartmental clearance, $Q_{m e} / F$ apparent THRX-195518 intercompartmental clearance, $R S E$ relative standard error, $V_{l} / F$ apparent revefenacin volume of the central compartment, $V_{2} / F$ apparent revefenacin volume of the peripheral compartment, $V_{3} / F$ apparent THRX-195518 volume of the central compartment, $V_{4} / F$ apparent THRX-195518 volume of the peripheral compartment the urine and feces (21\%) following a single IV dose in the human absorption, distribution, and metabolism, and excretion study [6].

The model for THRX-195518 used the post-hoc individually estimated revefenacin PK parameters for each individual subject as the basis for the kinetics of THRX-195518 formation in the dataset. THRX-195518 pharmacokinetics was best described by a two-compartment model (Fig. 1) with a fixed value for $\mathrm{F}_{\text {met }}$ and $\mathrm{PK}$ characteristics parameterized by $\mathrm{CL}_{\text {met }} / \mathrm{F}, V_{3} / \mathrm{F}, Q_{\text {met }} / \mathrm{F}$, and $V_{4} / \mathrm{F}$ with IIV terms on $\mathrm{CL}_{\text {met }} / \mathrm{F}$ and $V_{3} / \mathrm{F}$ with a combination additive and proportional residual error model for phase II study data and a separate proportional residual error model for phase III study data (Table 2). Inter-individual variability in the PK parameters $\mathrm{CL}_{\text {met }} / \mathrm{F}$ and $V_{3} / \mathrm{F}$ was moderate $(36.0 \%$ and $52.1 \%$ ). The corresponding $\eta$-shrinkage for the THRX-195518 model was $30.5 \%$ for $\mathrm{CL}_{\text {met }} / \mathrm{F}$.

\subsection{Covariate Analysis}

Covariates of age, weight, sex, race, smoking status, creatinine clearance, body mass index, and baseline $\mathrm{FEV}_{1}$ were tested for significance on the $\mathrm{PK}$ parameters $\mathrm{CL} / \mathrm{F}, V_{1} / \mathrm{F}$, $Q / \mathrm{F}, V_{2} / \mathrm{F}, \mathrm{CL}_{\text {met }} / \mathrm{F}, \mathrm{F}_{\text {met }}, Q_{\text {met }} / \mathrm{F}$, and $V_{4} / \mathrm{F}$. Additionally, the effects of baseline $\mathrm{FEV}_{1}$ were tested on the PK parameters
$\mathrm{CL} / \mathrm{F}, V_{1} / \mathrm{F}, Q / \mathrm{F}$, and $V_{2} / \mathrm{F}$ because of the potential impact of respirational capacity on the kinetics of revefenacin absorption. The effect of liver enzymes was included by the addition of alanine aminotransferase, aspartate aminotransferase, and total bilirubin as covariates on the formation and clearance of THRX-195518. Hepatobiliary elimination of revefenacin was assumed from the results of the absorption, distribution, and metabolism, and excretion study indicating the clearance of revefenacin via hepatobiliary elimination [6] and data from the hepatic impairment study demonstrating increased exposures to THRX-195518 in patients with moderate hepatic impairment [10].

The covariate analysis identified age as a statistically significant covariate on $\mathrm{CL} / \mathrm{F}$, and body weight was a significant covariate on $Q / F$ of revefenacin. Age was identified as a statistically significant covariate on $\mathrm{CL}_{\text {met }} / \mathrm{F}$, and body weight as a statistically significant covariate on $\mathrm{F}_{\text {met }}$.

For every $10 \%$ increase in age from 64 years, CL/F decreases by approximately $6 \%$. In addition, for every $10 \%$ increase in weight from $81 \mathrm{~kg}$, the $Q / \mathrm{F}$ increases by approximately $5 \%$. To estimate the effect of age on revefenacin pharmacokinetics, a simulation of 2000 patients with the study median age of 64 years was compared with 2000 simulated concentration profiles of identical patients at 40 and 85 years of age. To estimate the effect of weight on revefenacin 
pharmacokinetics, the simulation was repeated in patients with a median body weight of $81 \mathrm{~kg}$ and compared to otherwise identical patients with body weights of 50 and $150 \mathrm{~kg}$.

There is considerable overlap in the steady-state revefenacin PK profile and exposure over the entire age and weight range of patients in the study (Fig. 2a). The AUC $0-24$ in the median (64-year-old) subject following a 175- $\mu \mathrm{g}$ dose is predicted to be $0.332 \mathrm{ng} \cdot \mathrm{h} / \mathrm{mL}$ (covariance $74.8 \%$ ). The corresponding predicted revefenacin exposures are $24 \%$ lower in a younger 40-year-old subject, and $18 \%$ higher in an older 85-year-old subject. The corresponding predicted revefenacin exposures are $3 \%$ lower in a 50-kg subject and the same as a $150-\mathrm{kg}$ subject. A comparison of the individually predicted revefenacin exposures of all patients in the phase III patients does not indicate any significant differences across different age groups and weights (Fig. 2b). The effect of age and weight on revefenacin exposure is therefore considered to be minimal and does not warrant any dose adjustment. Effects of age and weight on THRX-195518 pharmacokinetics are further described in the ESM (Fig. S1a and b).

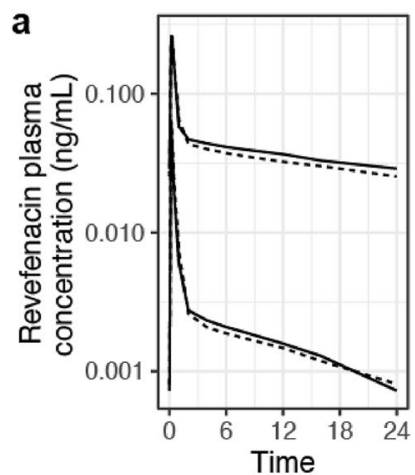

Category

- Median

-.. $50 \mathrm{~kg}$

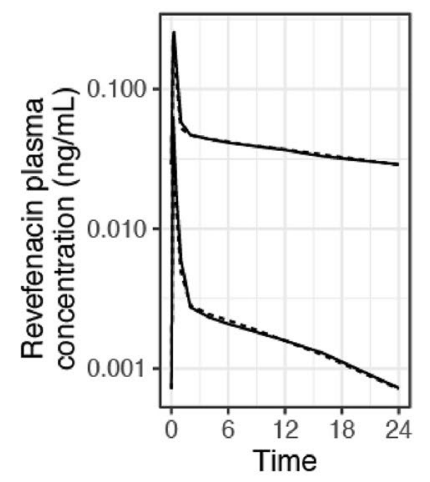

Category

- Median

-... $150 \mathrm{~kg}$

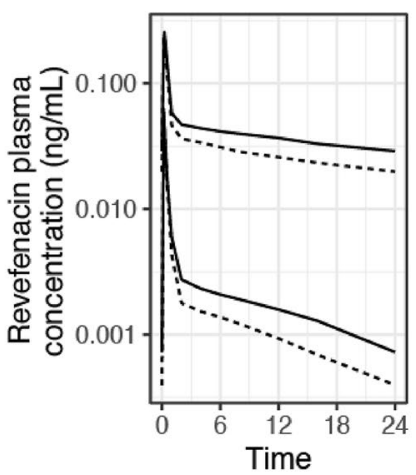

Category

- Median

-.. 40 years

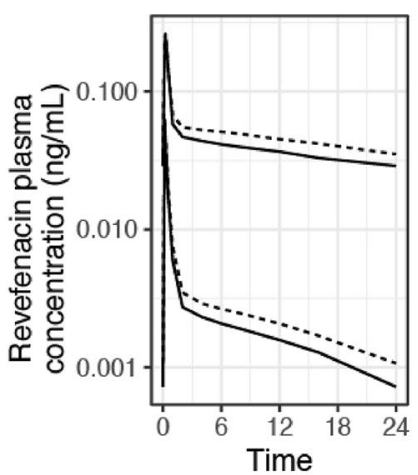

Category

- Median

-... 85 years

b
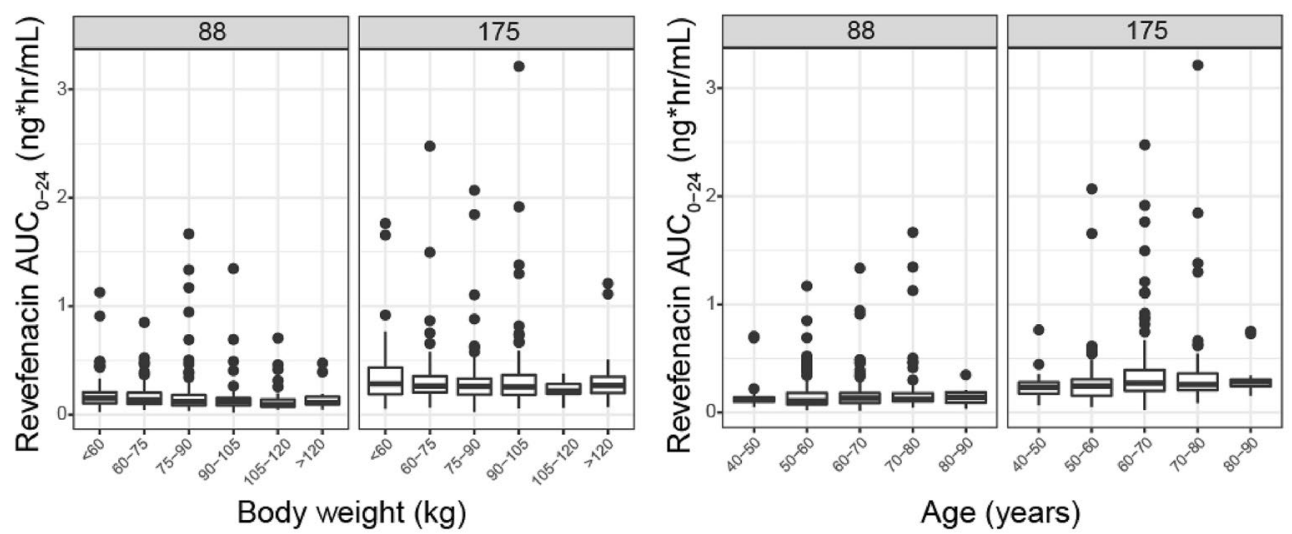

Fig. 2 Effect of age and weight on a individually predicted steady-state revefenacin plasma pharmacokinetic (PK) profiles [95\% prediction interval (PI)] after a $175-\mu \mathrm{g}$ dose and $\mathbf{b}$ exposures in patients from phase III studies. $A U C_{0-24}$ steady-state exposure 
The effect of age, weight, sex, smoking status, and concomitant LABA/ICS therapy on exposure $\left(\mathrm{AUC}_{0-24}\right.$ and $C_{\max }$ ) was evaluated by comparing the individually predicted revefenacin and THRX-195518 exposures of all patients in the phase III studies. No clinically meaningful effect of age, weight, sex, smoking status, and concomitant LABA/ ICS therapy was observed on exposure ( $\mathrm{AUC}_{0-24}$ and $\left.C_{\max }\right)$ (Fig. 3a, b), and therefore, these intrinsic and extrinsic factors do not warrant any dose adjustment.

\subsection{Sensitivity Analysis}

The final model was re-estimated using a lower and higher value for the rate of absorption, $K_{a},(100$ and $1000 / \mathrm{h}$ vs $200 / \mathrm{h}$ in the final model) and did not result in an improvement of the fit based on the value of the $-2 \log$-likelihood function $(p<0.1)$. The revefenacin and THRX-195518 $\mathrm{AUC}_{0-24}$ and $C_{\max }$ values predicted using the population PK model with and without the inclusion of quantifiable pretreatment
Fig. 3 Effect of age, sex, smoking status, and weight on the steady-state plasma a revefenacin and b THRX-195518 exposure. $A U C$ area under the curve, $C_{\max }$ maximum exposure, $P K$ pharmacokinetic a

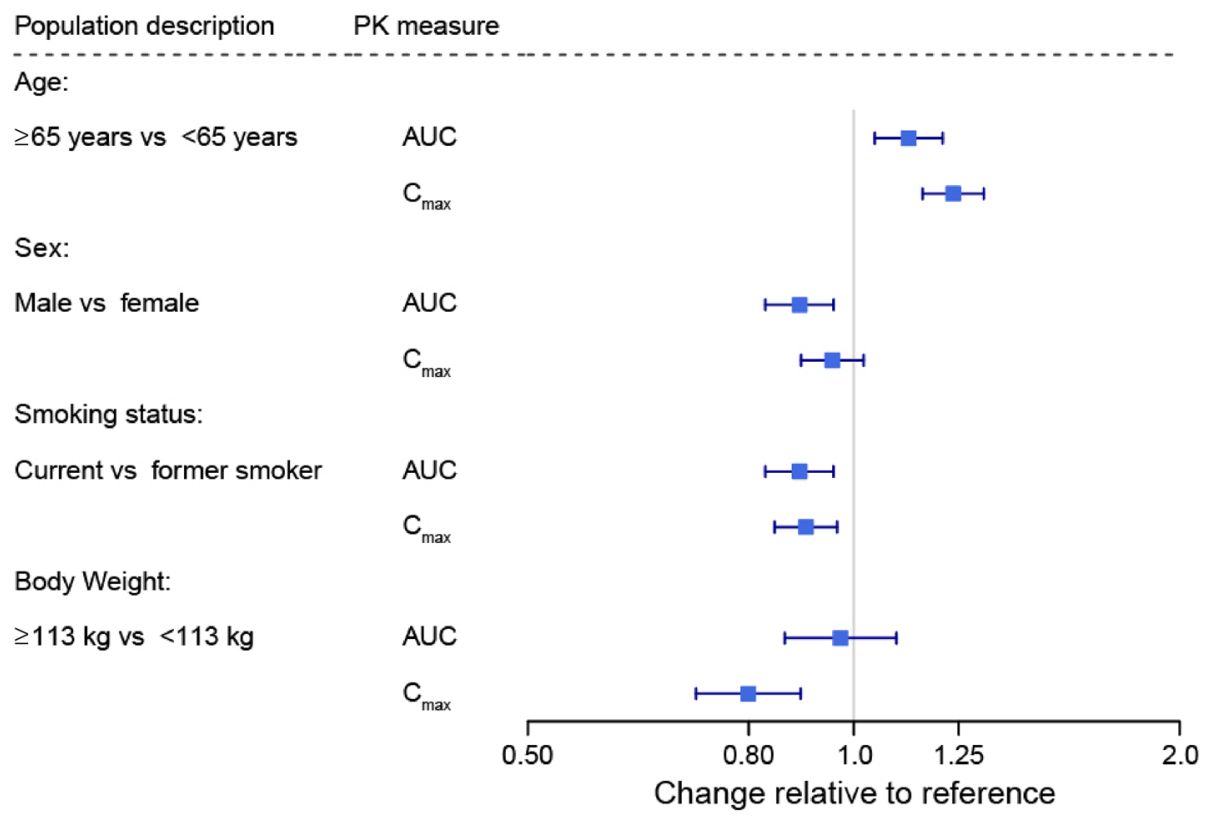

b

THRX-195518

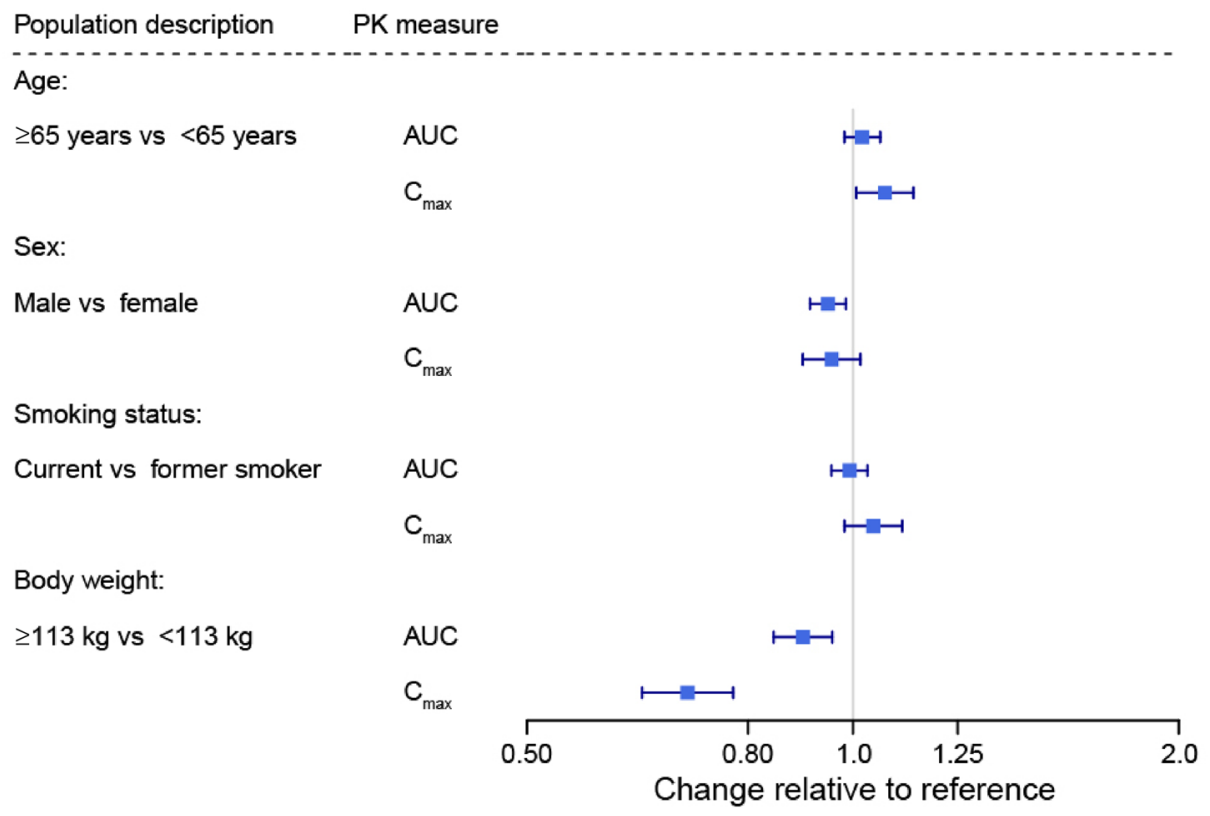


values showed minimal differences, with a point estimate of $0.0072 \mathrm{ng} / \mathrm{mL}$ for the residual additive error. The inclusion of the quantifiable pretreatment values reduced the mean predicted steady-state revefenacin $\mathrm{AUC}_{0-24}$ estimates by $8 \%$ at the $88-\mu \mathrm{g}$ dose $(0.170-0.157 \mathrm{ng} \mathrm{h} / \mathrm{mL})$ and by $3 \%$ at the $175-\mu \mathrm{g}$ dose $(0.329-0.319 \mathrm{ng} \mathrm{h} / \mathrm{mL})$, and the THRX$195518 \mathrm{AUC}_{0-24}$ estimates were reduced by $7 \%$ at the $88-\mu \mathrm{g}$ dose $(0.426-0.396 \mathrm{ng} \mathrm{h} / \mathrm{mL})$ and by $1 \%$ at the $175-\mu \mathrm{g}$ dose (0.859-0.849 $\mathrm{ng} \mathrm{h} / \mathrm{mL})$. The mean predicted steady-state $\mathrm{C}_{\max }$ estimates for revefenacin and THRX-195518 were nearly identical. Further analysis was conducted on data from the phase II studies only, which did not have quantifiable pretreatment concentrations. The resulting covariate effects determined by the phase II only model and phase II/III combined model were in agreement. Therefore, the inclusion of quantifiable pretreatment concentrations in the dataset did not significantly alter the results of the analysis.

\subsection{Model Evaluation}

\subsubsection{Revefenacin}

The predicted concentrations adequately match the observed concentrations at concentrations lower than $0.300 \mathrm{ng} / \mathrm{mL}$ (Fig. 4a). At higher concentrations associated with revefenacin doses $\geq 350 \mu \mathrm{g}$, the fitted model slightly under-predicts the plasma concentrations of revefenacin immediately following the end of drug nebulization. At the lower predicted concentrations, there is a group of observations where little to no revefenacin was expected, but detectable concentrations were measured (Fig. 4a). These observations reflect pre-dose trough samples collected in the phase III studies on days $15,29,57$, or 84 , where higher than expected concentrations of the drug were detected. These results may be due to sample handling or contamination issues; however, they were not removed from the PK analysis dataset because no attributable cause could be identified in the electronic records. The residual and weighted residual plots do not show any obvious trends (Fig. S2a and b of the ESM).

\subsubsection{THRX-195518}

The predicted THRX-195518 concentrations adequately match the observed concentrations at concentrations lower than $0.300 \mathrm{ng} / \mathrm{mL}$ (Fig. 4b). At higher THRX-195518 concentrations associated with revefenacin doses $\geq 350 \mu \mathrm{g}$, the fitted model slightly under-predicts the plasma concentrations of revefenacin. The residual and weighted residual plots do not show any obvious trends (Fig. S3a and b of the ESM). The bootstrap analysis indicated that the relationship of the estimated parameters from the final model is consistent with the estimates derived from 200 different datasets of the same size as the original dataset generated by sampling from the original dataset with replacement. a

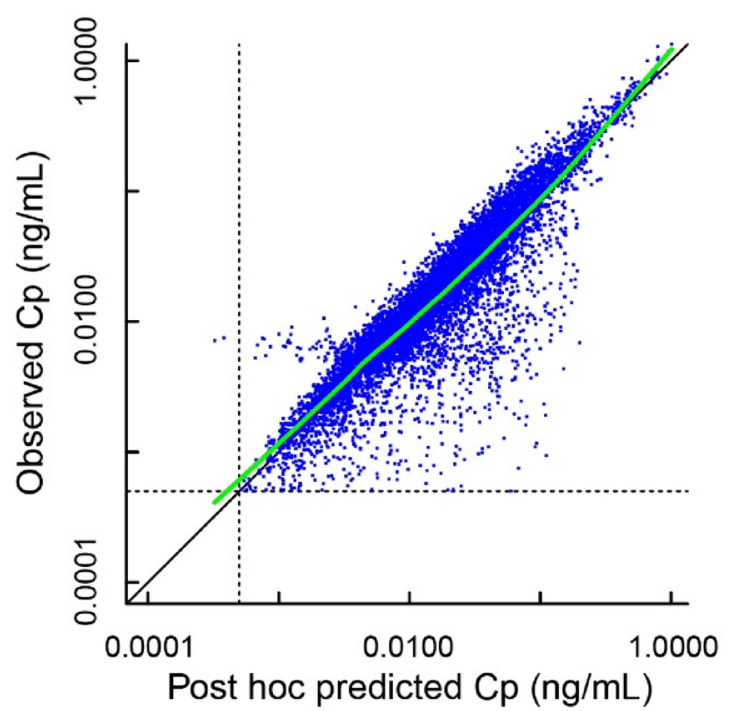

b

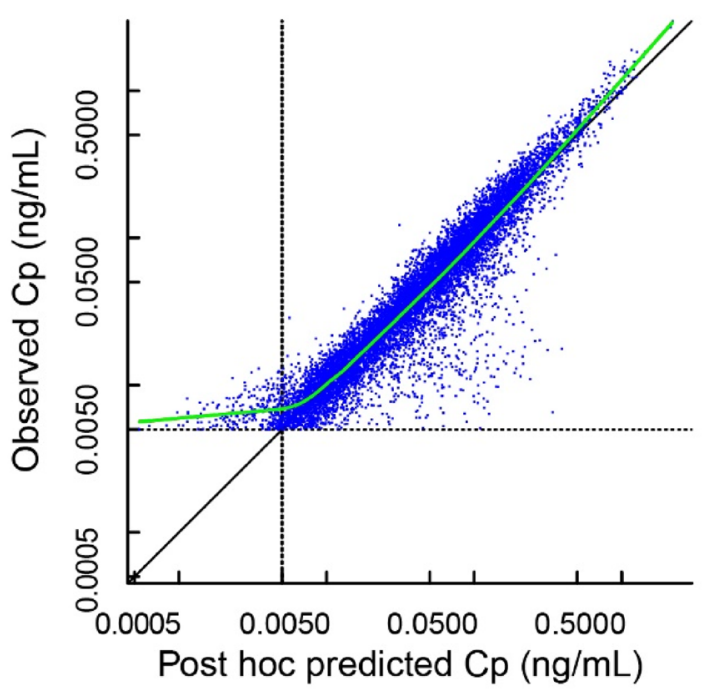

Fig. 4 Observed vs post-hoc predicted plasma concentrations for final revefenacin (a) and THRX-195518 (b) models. $C p$ plasma concentration 


\section{Discussion}

A population PK approach was used to evaluate the effects of relevant demographic and clinical covariates and to explore clinical factors that might affect revefenacin exposure in individual patients with COPD. The impact of demographic and clinical covariates, including those previously identified as significant covariates (e.g., age, body weight, renal function, smoking status) for other inhaled muscarinic antagonists [11,12], on the pharmacokinetics of revefenacin and THRX-195518 was assessed.

Across the clinical dose range, the PK profiles of revefenacin and THRX-195518 were both adequately described by a two-compartment open model with first-order clearance. A small dose effect on the fraction of revefenacin absorbed was identified, where the $175-\mu \mathrm{g}$ dose was estimated to be $7 \%$ more absorbed than the $88-\mu \mathrm{g}$ dose. Covariates including age, body weight, body mass index, sex, race, estimated creatinine clearance, baseline plasma alanine aminotransferase, aspartate aminotransferase, total bilirubin, smoking status, baseline $\mathrm{FEV}_{1}$, and concomitant LABA/ICS therapy did not affect the pharmacokinetics of revefenacin or THRX-195518. Age and body weight were identified as statistically significant covariates for revefenacin (age on CL/F and body weight on $Q / F$ ), and for THRX-195518 (age on CL/F, body weight on THRX-195518 formation), but the sensitivity analysis suggested that there would be no clinically relevant impact on revefenacin or THRX-195518 exposure ( $\mathrm{AUC}_{0-24}$ or $C_{\text {max }}$ ) at steady state. Although increased age has been associated with a decline in hepatic function [13], the lack of a significant correlation between the markers of hepatic function and the PK parameters in the model suggests that age may affect clearance independent of liver function.

The results of the current analysis may be limited by the analysis population, which consisted of mostly white patients $(90.3 \%)$. Future studies in other races may be helpful to generalize the current results across a larger population. Formal assessments of drug-drug interaction and concomitant medications were not conducted because of the phase III trial setting and lack of in vitro drug-drug interaction concerns identified for revefenacin.

Revefenacin is delivered directly to the lung and has poor oral absorption [6]. Thus, systemic levels of a parent drug and/or metabolite are not expected to significantly contribute to the lung (or local) PK effects of revefenacin administration. The systemic exposures of revefenacin and its major metabolite following inhaled administration in patients with COPD are low relative to concentrations necessary to antagonize muscarinic receptor function [14]. The low concentrations of revefenacin and THRX-195518 are expected to result in minimal systemic adverse effects of revefenacin consistent with the low observed incidence of antimuscarinic adverse events [1-3]. This observation is supported by the lack of exposure-response on heart rate, a biomarker for systemic M2-mediated antimuscarinic effects [1]. Additionally, revefenacin has exhibited a favorable safety profile in patients with COPD over a wide range of inhaled doses (up to $700 \mu \mathrm{g}$ for 7 days), several-fold above the clinical dose of $175 \mu \mathrm{g} /$ day [1-3]. Revefenacin (175 $\mu \mathrm{g} /$ day) was also shown to be well tolerated over 52 weeks of treatment [4]. Taken together, no dose adjustment is necessary based upon age, weight, sex, estimated creatinine clearance, baseline liver function tests, smoking status, and concomitant LABA/ICS therapy.

\section{Conclusions}

The sequential modeling approach resulted in a combined PK model that adequately characterized the pharmacokinetics of revefenacin and its major metabolite THRX-195518 in patients with COPD. No clinically significant impacts of patient and disease characteristics on revefenacin and THRX-195518 systemic exposure were identified, and thus no dose adjustments to account for intrinsic or extrinsic factors are necessary.

\section{Declarations}

Funding Medical writing and editorial support funded by Theravance Biopharma US, Inc. (South San Francisco, CA, USA) and Mylan Inc. (Canonsburg, PA, USA) were provided by Gautam Bijur, PhD, and Frederique H. Evans, MBS, of Ashfield Healthcare Communications.

Conflict of Interest Arthur Lo and David L. Bourdet are employees of Theravance Biopharma US, Inc. Marie T. Borin is a consultant for Theravance Biopharma US, Inc.

Ethics Approval N/A.

Consent to Participate N/A.

Consent for Publication N/A.

Data Availability All authors had access to the data included in the article. The datasets generated during the current study are not publicly available but can be requested from the corresponding author.

Code Availability N/A.

Author Contributions AL designed the research, performed the research, analyzed the data, and wrote the manuscript. MB and DB designed the research, performed the research, and wrote the manuscript.

Open Access This article is licensed under a Creative Commons Attribution-NonCommercial 4.0 International License, which permits any non-commercial use, sharing, adaptation, distribution and reproduction in any medium or format, as long as you give appropriate credit to the 
original author(s) and the source, provide a link to the Creative Commons licence, and indicate if changes were made. The images or other third party material in this article are included in the article's Creative Commons licence, unless indicated otherwise in a credit line to the material. If material is not included in the article's Creative Commons licence and your intended use is not permitted by statutory regulation or exceeds the permitted use, you will need to obtain permission directly from the copyright holder. To view a copy of this licence, visit http://creativecommons.org/licenses/by-nc/4.0/.

\section{References}

1. Pudi KK, Barnes CN, Moran EJ, Haumann B, Kerwin E. A 28-day, randomized, double-blind, placebo-controlled, parallel group study of nebulized revefenacin in patients with chronic obstructive pulmonary disease. Respir Res. 2017;18(1):182. https ://doi.org/10.1186/s12931-017-0647-1.

2. Quinn D, Barnes CN, Yates W, Bourdet DL, Moran EJ, Potgieter $\mathrm{P}$, et al. Pharmacodynamics, pharmacokinetics and safety of revefenacin (TD-4208), a long-acting muscarinic antagonist, in patients with chronic obstructive pulmonary disease (COPD): results of two randomized, double-blind, phase 2 studies. Pulm Pharmacol Ther. 2018;48:71-9. https://doi.org/10.1016/j. pupt.2017.10.003.

3. Ferguson GT, Feldman G, Pudi KK, Barnes CN, Moran EJ, Haumann B, et al. Improvements in lung function with nebulized revefenacin in the treatment of patients with moderate to very severe COPD: results from two replicate phase III clinical trials. Chronic Obstr Pulm Dis. 2019;6(2):154-65. https://doi.org/10.15326/ jcopdf.6.2.2018.0152.

4. Donohue JF, Kerwin E, Sethi S, Haumann B, Pendyala S, Dean $\mathrm{L}$, et al. Revefenacin, a once-daily, lung-selective, long-acting muscarinic antagonist for nebulized therapy: safety and tolerability results of a 52-week phase 3 trial in moderate to very severe chronic obstructive pulmonary disease. Respir Med. 2019;153:38433. https://doi.org/10.1016/j.rmed.2019.05.010.

5. Mylan. YUPELRI (revefenacin): US prescribing information. 2018. http://www.fda.gov. Accessed 13 Nov 2018.

6. Bourdet D, Yeola S, Colson P-J, Pendyala S, Barnes CN, Borin M. Absorption, distribution, metabolism, and excretion of revefenacin, a long-acting muscarinic antagonist (LAMA), in healthy male subjects. Am J Respir Crit Care Med. 2018;197:A-3033A. https://doi.org/10.1164/ajrccm-conference .2018.197.1_MeetingAbstracts.A3033.

7. US Department of Health and Human Services. Food and Drug Administration. Integrated addendum to ICH harmonised guideline: guideline for good clinical practice E6 (R2). 2018. https:// www.fda.gov/media/93884/download. Accessed 15 Jan 2020.

8. Lo A, Borin MT, Bourdet DL. Sequential modeling of the population pharmacokinetics of revefenacin and its major metabolite in COPD patients. J Pharmacokinet Pharmacodyn. 2018;45(1):3134. https://doi.org/10.1007/s10928-018-9606-9.

9. Ahn JE, Karlsson MO, Dunne A, Ludden TM. Likelihood based approaches to handling data below the quantification limit using NONMEM VI. J Pharmacokinet Pharmacodyn. 2008;35(4):40121. https://doi.org/10.1007/s10928-008-9094-4.

10. Borin MT, Lo A, Barnes CN, Pendyala S, Bourdet DL. Pharmacokinetics and safety of revefenacin in subjects with impaired renal or hepatic function. Int J Chron Obstruct Pulmon Dis. 2019;14:2305-18. https://doi.org/10.2147/copd.S203709.

11. Goyal N, Beerahee M, Kalberg C, Church A, Kilbride S, Mehta R. Population pharmacokinetics of inhaled umeclidinium and vilanterol in patients with chronic obstructive pulmonary disease. Clin Pharmacokinet. 2014;53(7):637-48. https://doi.org/10.1007/ s40262-014-0143-4.

12. Mehta R, Farrell C, Hayes S, Birk R, Okour M, Lipson DA. Population pharmacokinetic analysis of fluticasone furoate/umeclidinium bromide/vilanterol in patients with chronic obstructive pulmonary disease. Clin Pharmacokinet. 2020;59(1):67-79. https ://doi.org/10.1007/s40262-019-00794-w.

13. Tan JL, Eastment JG, Poudel A, Hubbard RE. Age-related changes in hepatic function: an update on implications for drug therapy. Drugs Aging. 2015;32(12):999-1008. https://doi.org/10.1007/ s40266-015-0318-1.

14. Hegde SS, Pulido-Rios MT, Luttmann MA, Foley JJ, Hunsberger GE, Steinfeld T, et al. Pharmacological properties of revefenacin (TD-4208), a novel, nebulized long-acting, and lung selective muscarinic antagonist, at human recombinant muscarinic receptors and in rat, guinea pig, and human isolated airway tissues. Pharmacol Res Perspect. 2018;6(3):e00400. https://doi. org/10.1002/prp2.400. 